\title{
Characterisation of Fibre Reinforced Resin Concrete
}

\author{
KIRUTHIKA CHANDRASEKARAN*, LAVANYA PRABHA SRINIVASAN, \\ NEELAMEGAM MEYAPPAN \\ Department of Civil Engineering, Easwari Engineering College, Ramapuram, Chennai, 600089, Tamilnadu, India
}

\begin{abstract}
Resin Concrete uses polymeric resin to replace cement concrete. Four types of polyester resins were identified with Methyl methacrylate as catalyst, calcium carbonate and fly ash as fillers along with river sand and coarse aggregate size of $10 \mathrm{~mm}$, $6 \mathrm{~mm}$ were used to produce resin concrete. Seventytwo trial batches were carried out for preliminary investigation targeting compressive strength of more than $80 \mathrm{MPa}(11.6 \mathrm{ksi})$ and four batches were shortlisted. These four batches along with the addition of glass fiber were taken for detailed investigation of stress strain behavior, young's modulus, Poisson ratio, various correlative equations among their mechanical properties and durability properties. Developed mix can be recommended for manufacturing various polymer products.
\end{abstract}

Keywords: resin concrete, unsaturated polyester resins, glass fibre, Young's modulus, Poisson ratio, correlative equations

\section{Introduction}

Resin Concrete (RC) is a type of concrete which consists of resin, filler and aggregate mixture. Development of resin concrete dates back to early 1950s in which they replaced the cement and used resins as binder for some specific applications. Japan, United States, United Kingdom, European countries are widely using this type of concrete in manufacturing various products because of its superior mechanical and durability related property, rapid curing and excellent bond strength [1]. The main objective of this study is to develop the technology for manufacturing various polymer based products possessing higher mechanical and durability properties which are listed as follows.

-To develop the mix for resin concrete with higher mechanical and durability properties;

-To optimize the material for filler and resin types with the addition of glass fibers;

-To study the mechanical properties of resin concrete for sizing effect;

-To study the mechanical properties of resin concrete under different curing regime;

-To study the stress strain relationship of the developed mix;

-To derive the various correlative equations between flexural, direct tensile strength, UPV values with compressive strength.

Commonly used resins for RC are unsaturated polyester resin, methyl methacrylate (MMA), epoxy resins, furan resins, vinyl ester resins, polyurethane resins and urea formaldehyde resins. Furan resins are widely used in the European countries and MMA has limited applications because of its higher flammability property and disagreeable odour. However, MMA received few attentions because of its good workability and low temperature curability [2].

The choice of particular type of resin is based on the factors like cost, availability, good mechanical properties, and chemical resistance. For harsh environmental factors, epoxy resins are preferred over polyester resins for its better mechanical and durability properties. But the epoxy resins are less economical compared to the polyester resin types. Hence based on the factors like low cost, easy availability and good mechanical properties, unsaturated polyester resin types are selected for this study [3]. Earlier researches on polyester resin with $12 \%$ to $14 \%$ resin of concrete results showed the compressive strength of range 60 to $80 \mathrm{MPa}$ and flexural strength of about 6 to $8 \mathrm{MPa}$. Hence this study targets the strength of more than $80 \mathrm{MPa}$ using industrial waste and minimum optimized resin percentage

*email: dckiruthika@yahoo.co.in 
to obtain high performance concrete with higher mechanical and durability properties.

Other ingredients of RC consists of fillers and aggregate mixture. Two different fillers such as calcium carbonate and fly ash were used as fillers. Generally, 75 to $80 \%$ volume of the RC are occupied by aggregate and fillers. Aggregates are added in two different groups such as fine aggregate and coarse aggregate.

The properties of RCs are based on the conditions of preparation. Binder content, aggregate particle size, types and content of micro fillers and curing conditions have great impact on properties of RC. By taking all these factors, resin concrete is firstly optimized for the mix proportion for each ingredient to get the high compressive strength of more than $80 \mathrm{MPa}(11.6 \mathrm{ksi})$ and later detailed investigation on mechanical properties, durability properties, study of correlation among the mechanical properties are studied for the optimized mix and material.

\subsection{Research significance}

-Environmental aspects: Resin concrete completely avoids the usage of cement and water as binder thereby avoiding the $\mathrm{CO}_{2}$ emissions from cement manufacturing industries.

-Scientific importance: The developed resin concrete can produce greater compressive strength, resistant against corrosion.

-Industrial importance: The low permeability, chemical resistance of resin concrete allows it to be used in Swimming pools, Sewer structure applications, Chemical storage tanks and pipes.

-Social importance: Resin concrete is of zero scrap value, low maintenance and repair cost.

\section{Materials and methods}

\subsection{Materials}

\subsubsection{Resins}

Resins can be available as monomer and pre-polymer. In this study, monomer is used. It is converted into polymer by the process called polymerization by addition of initiator such as catalyst and accelerator to the liquid resin. Unsaturated polyester resins such as isophthalic resin (I), orthophthalic resin (O), combination of isophthalic resin with 10\% methyl methacrylate (IM) and combination of $\mathrm{O}$ with $10 \%$ IM were taken. Dicorboxylic acids and dihydroxy alcohols on polycondensation process forms polyesters. I and $\mathrm{O}$ resins are formed from phtalic acids of different diacids. Various binder properties of 4 different types of resins are shown in Table 1 . Viscosity at $25^{\circ} \mathrm{C}$, cps Brookfield Viscometer LV DV +Pro Spindle 63, rpm 60 for all the resin types varies from $300-400$, Shelf life at $25^{\circ} \mathrm{C}$ for all the resin types are three months. Appearance of I type resin is straw yellowish clear liquid, O type resin is clear to pale yellowish liquid whereas IM and OM show pale yellowish clear liquid.

Table 1. Properties of different types of resin

\begin{tabular}{|c|c|c|c|c|}
\hline TYPE & I & IM & O & OM \\
\hline Specific gravity at $25^{\circ} \mathrm{C} \mathrm{gm} / \mathrm{mL}$ & 1.1 to 1.12 & 1.10 to 1.12 & 1.11 to 1.12 & 1.11 to 1.12 \\
\hline Acid value, $\mathrm{mg} \mathrm{KOH} / \mathrm{gm}$ & 15 to 20 & 15 to 19 & 23 to 27 & 20 to 24 \\
\hline Volatile content, $\%$ & 36 to 40 & 36 to 40 & 35 to 39 & 36 to 38 \\
\hline Gel time at $25^{\circ} \mathrm{C}, \mathrm{min}^{*}$ & 15 to 20 & 15 to 20 & 10 to 20 & 20 to 30 \\
\hline Peak exotherm ${ }^{\circ} \mathrm{C}^{* *}$ & 175 to 185 & 170 to 180 & 170 to 180 & 160 to 170 \\
\hline
\end{tabular}

\subsubsection{Initiators}

Initiators initiate the crosslinking between polyester and styrene molecules and convert the liquid resin into rigid solid. Catalyst and accelerator used as initiators in this study are Methyl Ethyl Ketone Peroxide (MEKP) and Cobalt Octoate (CO), respectively. About initiators of about $0.5 \%$ to $2 \%$ should be used by weight of resin, depending upon the required ambient temperature and setting time. In this study, accelerator of $1 \%$ and $1.5 \%$ catalyst by weight of resin is used. Thorough mixing of resin with initiators is suggested for optimum result and they should never be stored together or mixed as they 
would cause instant explosion. Hence, tightly closed containers preferably in atmosphere below $30^{\circ} \mathrm{C}$ in moisture free areas and kept away from direct sunlight, heat radiation and fire should be used.

\subsubsection{Fillers}

Two different fillers such as calcium carbonate and fly ash are used as fillers in this study. Fillers are generally added to fill the pores in between the fine and coarse aggregate and to avoid the voids. Filler percentage of $12 \%$ to $15 \%$ by weight of concrete is used in most of the studies to get the optmised mix proportion. Hence filler percentage of $15 \%$ by weigh of concrete is used in this study [4]. Filler are usually less than 150 micron particles size. Calcium carbonate is widely used mineral fillers in the plastics industry and its use in rigid packaging has increased now a days. Another filler used is a coal combustion product that is composed of the fine particles of burned fuel that are driven out of coalfired boilers together with the flue gases called fly ash. Bottom Ash that falls to the bottom of the firebox is used. The properties of calcium carbonate and fly ash as per the ASTM C 618 standards [5] are given in Table 2. These two types of fillers will greatly help in saving the energy and effectively using the industrial waste material so that it reduces the cost of resin concrete.

Table 2. Properties of fillers used

\begin{tabular}{|c|c|c|}
\hline & Calcium carbonate & $\begin{array}{c}\text { Fly ash } \\
\text { type } \mathrm{F}\end{array}$ \\
\hline $\mathrm{SiO}_{2}, \%$ & 0.7 & 62.5 \\
\hline $\mathrm{Al}_{2} \mathrm{O}_{3}, \%$ & 0.04 & 23.83 \\
\hline $\mathrm{CaO}, \%$ & 98 & 1.68 \\
\hline $\mathrm{MgO}, \%$ & 0.68 & 0.61 \\
\hline $\mathrm{K}_{2} \mathrm{O}, \%$ & - & 1.80 \\
\hline $\mathrm{MnO}_{0} \%$ & - & 0.055 \\
\hline $\mathrm{P}_{2} \mathrm{O}_{5}, \%$ & - & 0.91 \\
\hline $\mathrm{TiO}_{2}, \%$ & - & 1.71 \\
\hline $\mathrm{Na}_{2} \mathrm{O}_{2} \%$ & 0.16 & - \\
\hline $\mathrm{Fe}_{2} \mathrm{O}_{3}, \%$ & 0.04 & 6.28 \\
\hline $\mathrm{SO}_{3}, \%$ & - & 5 \\
\hline$-=\mathrm{not}_{\text {measured items. }}$ & &
\end{tabular}

\subsubsection{Aggregate mix}

The fine aggregate passing through $2.36 \mathrm{~mm}$ sieve and coarse aggregate sizes of aggregates passing through $10 \mathrm{~mm}$ and passing through $6.7 \mathrm{~mm}$ sieve and retained on $300 \mathrm{~mm}$ are used for all the trial batches. These samples are kept in hot air oven at $100^{\circ} \mathrm{C} \pm 5^{\circ} \mathrm{C}$ in order to remove any moist present in the aggregate. Moist sample will have huge impact in polymerization and it affects the strength of the concrete and hence maximum water content should be limited to $0.1 \%$ [6]. Hence these samples are oven dried for about four hours and cooled down to room temperature before use. These dried samples are taken and tried with various mix proportions of different sizes to calculate packing density of that material. After various trials batches showing dry packing density between 0.4 to 0.65 on aggregate mix, dry packing density of 0.55 are taken as optimized mix proportion for aggregates to reduce the maximum voids in the aggregate mix so that it leads to good compaction, increasing the strength of the concrete.

\subsubsection{Fibers}

There are different types of fibers such as glass, carbon, steel, polypropylene fibres etc are available in the market. Glass fibers are generally used to produce the fiber reinforced resin concrete to enhance the flexural properties of resin concrete. Albeit, glass fibre strength properties shown in Table 3 are somewhat lower than carbon fibre, it is less stiff, the material is typically far less brittle, and the raw materials are much less expensive. Its bulk strength and weight properties are also very favorable and it can be easily blended during mixing. 0 to $6 \%$ variations were carried out in different researches to obtain higher flexural properties [1]. In this study, $0.5 \%$ glass fibers of $25 \mathrm{~mm}$ length of total volume of resin concrete are used. 
Table 3. Properties of fiber used

\begin{tabular}{|c|c|}
\hline Glass fiber & Fiber property \\
\hline Length (mm) & 25 \\
\hline Density & 2.5 \\
\hline Young's modulus (GPa) & 70 \\
\hline Tensile strength (MPa) & $2000-3500$ \\
\hline Elongation at break (\%) & 2.5 \\
\hline
\end{tabular}

\subsection{Methodology}

\subsubsection{Sample preparation}

Samples are prepared by casting $40 \mathrm{~mm}$ x $40 \mathrm{~mm}$ x $40 \mathrm{~mm}$ cubes $(1.57 \mathrm{inch} \times 1.57 \mathrm{inch} \times 1.57 \mathrm{inch})$ for various trial batches and tested for preliminary compressive strength. As per the guidelines, more three times the maximum size of aggregate is sufficient for testing [7, 8]. Since the maximum size of aggregate used is $10 \mathrm{~mm}, 40 \mathrm{~mm}$ cube sizes which is greater than $30 \mathrm{~mm}$ are much satisfactory for initial investigation and later on it was checked with $70 \mathrm{~mm}$ cube sizes for sizing effect since fiber of $25 \mathrm{~mm}$ length was added to the optimised mix. For each trial, three identical cube samples of size 40mm (1.57 inch) were cast and tested for compressive strength. Thus for four types of resins, totally seventy two trial batches and two hundred and sixteen cubes were cast and tested.

This developed mix is then used for casting $70 \mathrm{~mm}$ cubes $(2.76 \mathrm{inch})$ to study the sizing effect compared with $40 \mathrm{~mm}$ (1.57 inch) cubes, beam of size $40 \mathrm{~mm} \times 40 \mathrm{~mm} \times 160 \mathrm{~mm}(1.57$ inch x 1.57 inch x $6.3 \mathrm{inch})$, cylinders of size $100 \mathrm{~mm}(3.94 \mathrm{inch})$ diameter and $200 \mathrm{~mm}(7.87 \mathrm{inch})$ height for detailed investigation on mechanical properties of resin concrete. $40 \mathrm{~mm}$ cubes $(1.57 \mathrm{inch})$ were used in the study of durability properties of concrete.

\subsubsection{Optimisation of mix}

All the ingredients should be optimized to get the high- performance resin concrete. Resin percentage optimized in the literature was about 10 to $14 \%$ by weight of total material for various type of unsaturated polyester resin concrete. These were taken as reference for trial batches for all types of resin and cubes of size $40 \mathrm{~mm} \times 40 \mathrm{~mm} \times 40 \mathrm{~mm}$ (1.57inch x $1.57 \mathrm{inch} \times 1.57 \mathrm{inch})$ are cast. These trial batches were targeted for obtaining high compressive strength of more than $80 \mathrm{MPa}(11.6 \mathrm{ksi})$. For each type of resin, trial batches such as $10 \%, 12 \%, 14 \%$ resin content as binder, calcium carbonate and fly ash as fillers of $15 \%$, aggregate sizes of $6 \mathrm{~mm}$ and $10 \mathrm{~mm}$ were taken for initial study on mechanical properties to obtain the desired strength. The initiators percentage used are $1.5 \%$ MEKP as catalyst and $1 \%$ cobalt octoate as accelerator by weight of resin content under normal room temperature. 72 trial batches were cast with each batch consists of 3 samples and the samples were allowed for air curing for a period of about 7 days and tested for compressive strength since compressive strength remains constant after 7 days $[3,6]$. Preliminary test results for optimizing the mix shows that, 1) on varying the resin percentage for all the 4 types, $10 \%$ resin is insufficient and workability is less. For $14 \%$, the resin content is high and it decreases the compressive strength in all the cases shown in Figure 1 Thus, $12 \%$ of resin is optimized for all the resin types, 2) $10 \mathrm{~mm}$ aggregate batches dominates the results compared to $6 \mathrm{~mm}$ aggregates and aggregate size of $10 \mathrm{~mm}, 3$ ) Descending order of 4 different types of resins based on the preliminary compressive test are as follows. $\mathrm{O} \rightarrow \mathrm{I} \rightarrow \mathrm{OM} \rightarrow \mathrm{IM}$ shown in Figure 1 and optimized mix is shown in Figure 2. 


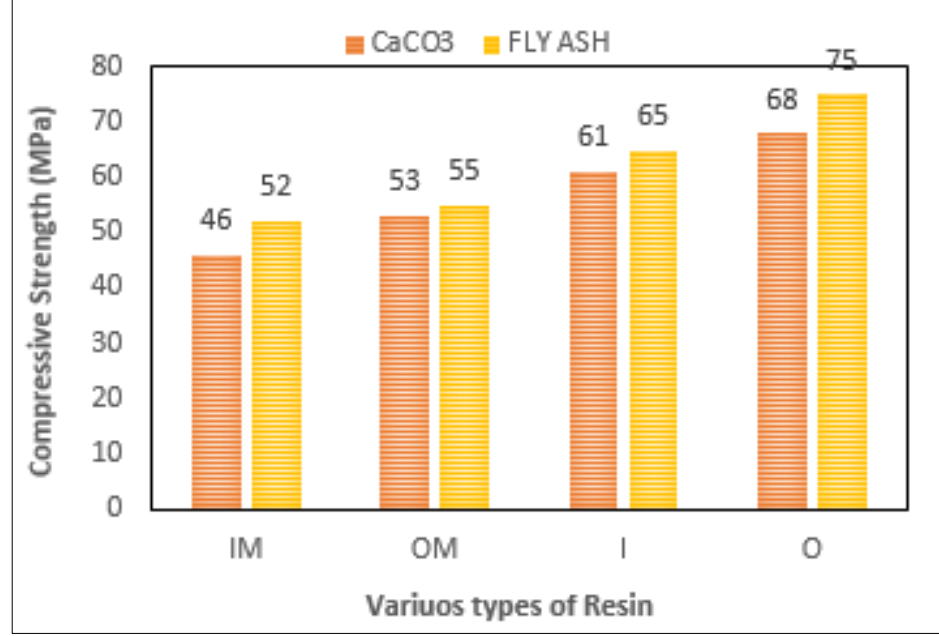

Figure 1. Compressive strength of various types of resins in 7 days $(\mathrm{MPa})$

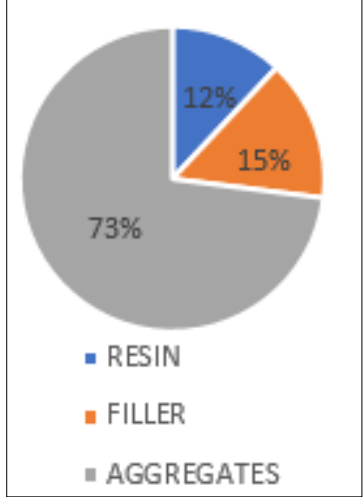

Figure 2. Optimized mix

\subsubsection{Optimization of materials}

From the preliminary study results, only two resin types I and $\mathrm{O}$ are chosen for further investigations. Out of these seventy two trial batches, only four batches were selected for detailed study of mechanical properties such as compressive strength, flexural strength and Split tensile strength to optimize the ingredient such as resin type and filler type. RC can also be reinforced with glass fibres of $25 \mathrm{~mm}$ length to develop a FRRC (Fibre Reinforced Resin Concrete) to increase the mechanical properties, energy absorption capacity and impact resistance. With the addition of glass fiber, factors such as sizing effect, curing under different regime were also studied for these 8 batches. The sample nomenclature are as follows.

Sample Nomenclature:

I- Isophthalic resin

O- Orthophthalic resin

C- Calcium carbonate without fibres

F- Fly ash without fibres

CF- calcium carbonate with glass fibres

FF- Fly ash with glass fibres

\section{Results and discussions}

\subsection{Mechanical properties of selected mix}

\subsubsection{Compressive Strength}

Three identical specimens of type $40 \mathrm{~mm}$ x $40 \mathrm{~mm}$ x $40 \mathrm{~mm}$ (1.57inch x $1.57 \mathrm{inch}$ x $1.57 \mathrm{inch})$ cube were cast and tested to evaluate the preliminary compressive strength of each type of mixtures. To study the sizing effect on compressive strength, samples of $70 \mathrm{~mm}$ cubes, were casted and tested (Figure 3,4). I and $\mathrm{O}$ type resins as binder are investigated with sizing effect such as action of $70 \mathrm{~mm}$ cubes compared with $40 \mathrm{~mm}$ (1.57inch) cubes under different curing regime such as the samples are cured at normal room temperature and at oven in $80^{\circ} \mathrm{C}$ for $8 \mathrm{~h}$. These batches were again experimented with the addition of glass fibers to produce FRRC.

The experimental results of compressive strength for I and $\mathrm{O}$ type resins with and without fibers are shown in Figure 5 for calcium carbonate samples and Figure 6 shows the experimental results of compressive strength for I and $\mathrm{O}$ type resins with and without fibers for fly ash samples. 


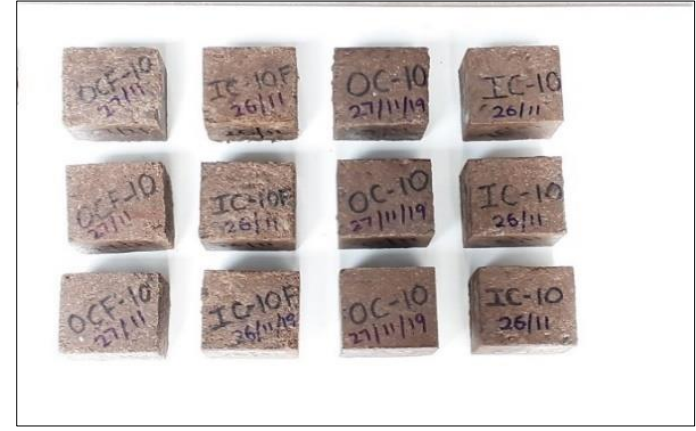

Figure 3.70mm Cubes with and without fibers for I and O type resins

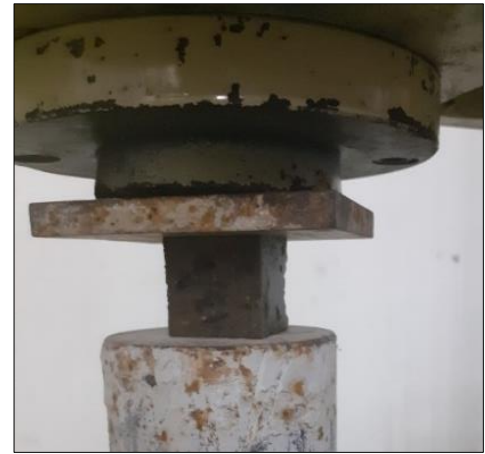

Figure 4. Testing Sample in UTM

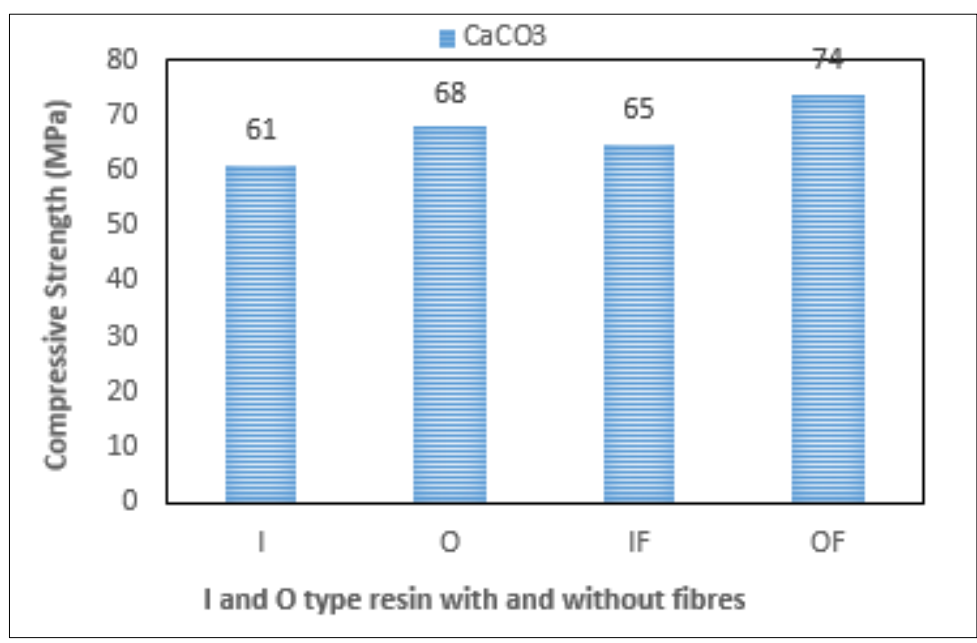

Figure 5. Compressive Strength of $\mathrm{CaCO}_{3}$ samples at 7 days

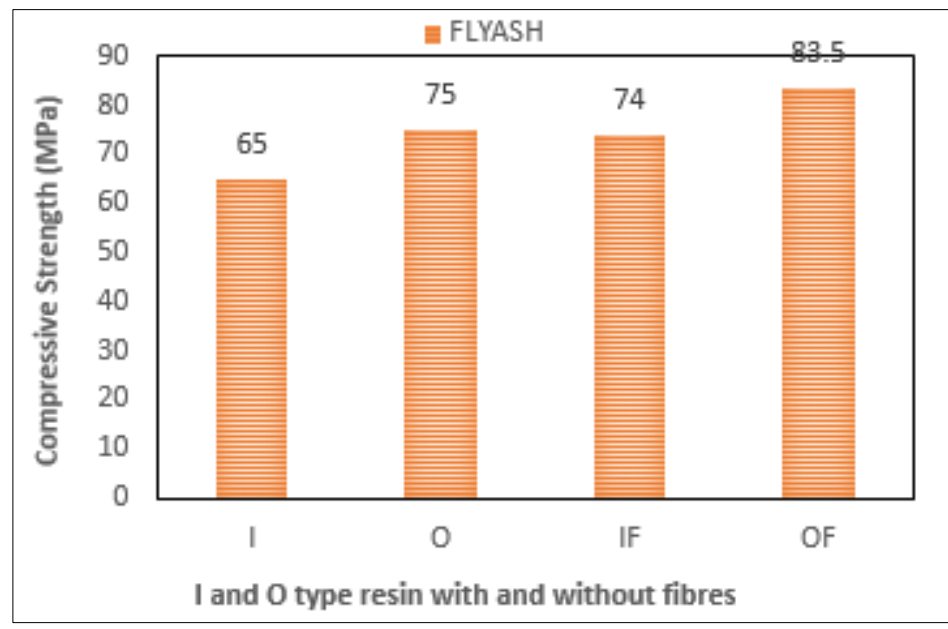

Figure 6. Compressive strength of fly ash samples at 7 days

\subsubsection{Flexural strength}

The beam specimen of size $40 \mathrm{~mm}$ x $40 \mathrm{~mm}$ x $160 \mathrm{~mm}$ (1.57inch x $1.57 \mathrm{inch} \times 6.3 \mathrm{inch})$ are tested under flexure using four-point loading method (Figure 7) using Universal testing machine for all the calcium carbonate and fly ash samples with and without fibers. Loads were applied 40mm (1.57 inch) from support on both sides at top of the specimen. Load $(\mathrm{P})$ is gradually applied on the specimen until the specimen got failure and the flexural strength determined is shown in Figure 8. The test results showed increased strength with the addition of fibers than the beams without fibres. In both resin types, fly ash 
shows increased strength than calcium carbonate samples. Also, $\mathrm{O}$ type resin shows a high flexural strength than that of I type resin.
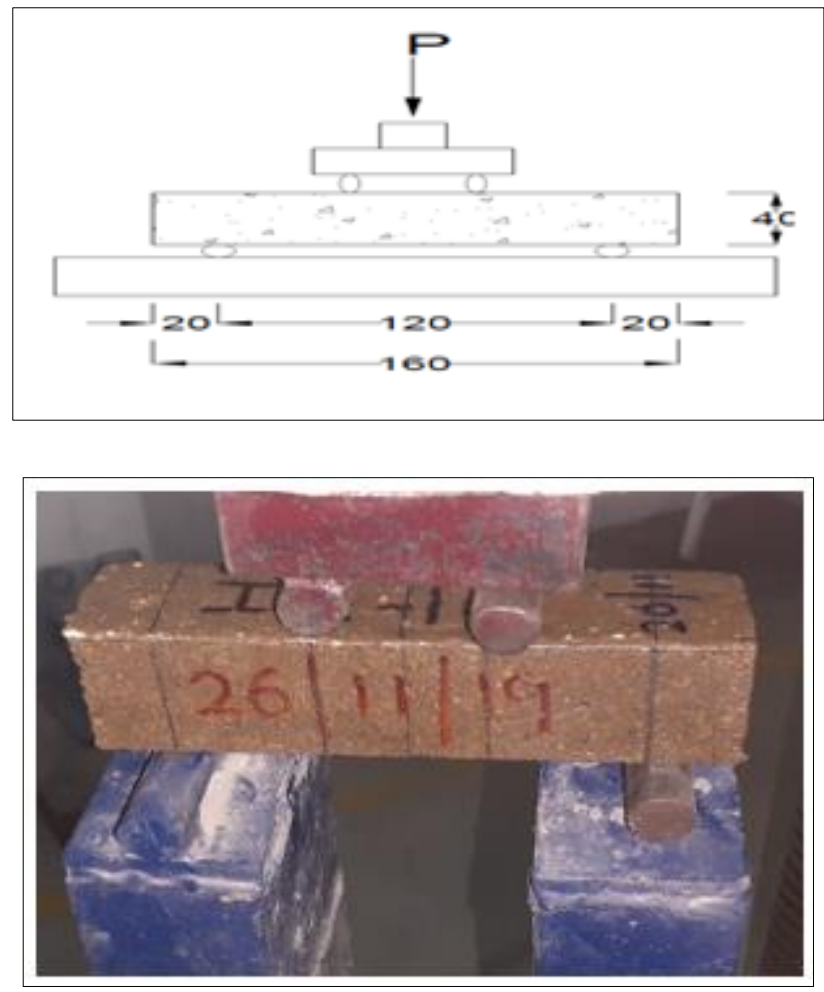

Figure 7. Test set up for flexure under 4 point static load (All dimensions are in $\mathrm{mm}$ ) $1 \mathrm{~mm}=0.039$ inches

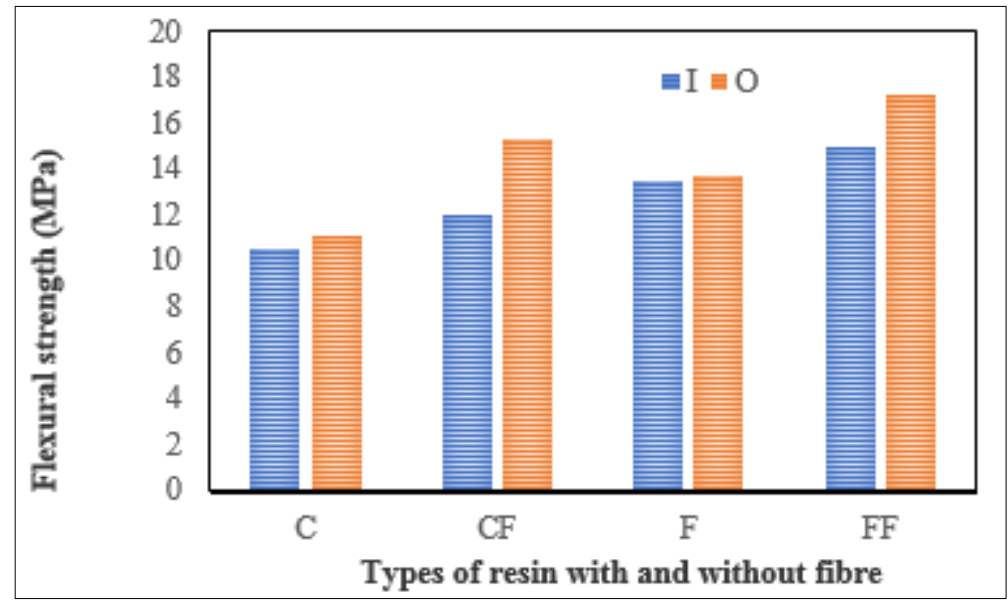

Figure 8. Average flexural strength of $\mathrm{I}$ and $\mathrm{O}$ type resins with and without fiber at 7 days $\left(\mathrm{CaCO}_{3}\right.$ and fly ash samples)

\subsubsection{Spilt tensile strength}

Cylindrical specimens of size $100 \mathrm{~mm}$ (3.94 inch) diameter and 200mm (7.87 inch) height were cast with and without glass fibres for both type of resins and tested for tensile strength. The obtained results showed similar kind of tensile strength with the addition of glass fibers of fly ash samples for both type of resins. Test results are shown in Figure 9. 


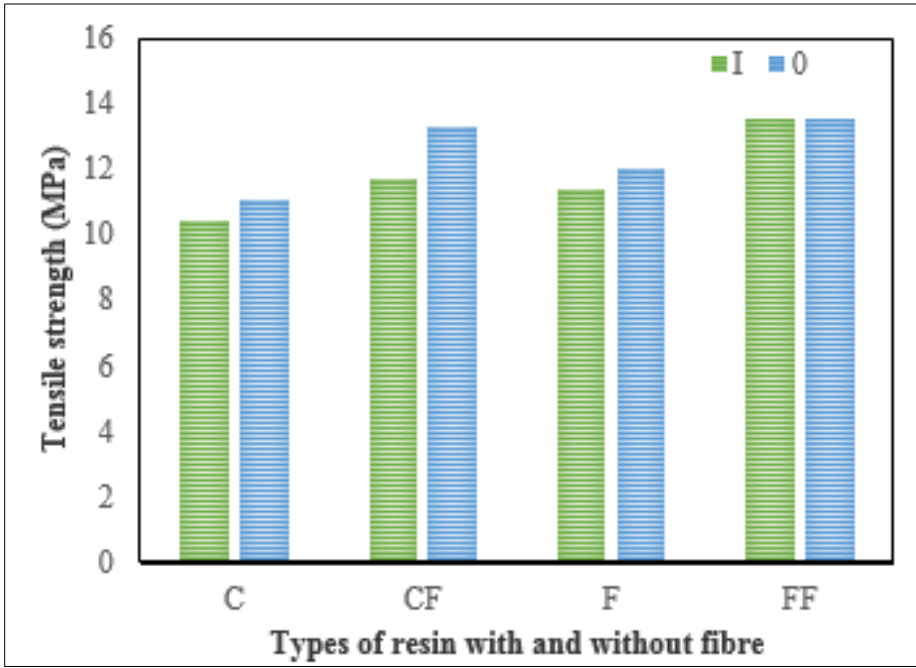

Figure 9. Average split tensile strength of I and O Type with and without fiber at 7 days $\left(\mathrm{CaCO}_{3}\right.$ and fly ash samples)

\subsection{Durability properties}

\subsubsection{Water Absorption test}

Water Absorption test is carried out to determine the durability or performance of resin concrete. Penetration of water due to capillary rise or due to the exterior surfaces exposed to aggressive environment will result in the reduction of strength and it highly affects the durability properties of concrete. The test is carried out as per ASTM D570 [9] in the hardened resin concrete as shown in Figure 10. Percentage of water absorption was calculated using this method and the results were found to be almost NIL which means that the concrete is impermeable and the resin works well as binder in RC.

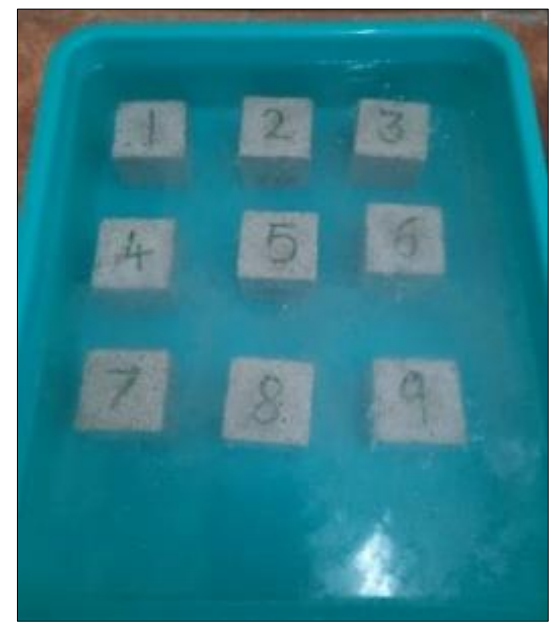

Figure 10. 40mm cubes immersed in water

\subsubsection{Acid tests}

Samples are subjected to acids to determine the performance of concrete under aggressive environment. Experimental investigation of the resin concrete of samples size $40 \mathrm{~mm}$ x $40 \mathrm{~mm} \times 40 \mathrm{~mm}$ (1.57inch $\times 1.57 \mathrm{inch} \times 1.57 \mathrm{inch}$ ) were studied. Two different types of dilute nitric acid and sulphuric acid were taken for this experimental study and the samples are immersed in 5\% dilute nitric acid (Figure 11) and 5\% dilute sulphuric acids (Figure 12). As a result, the normal cement concrete is completely disintegrated with 2 to $5 \%$ dilute of nitric and sulphuric acids and the committee recommends the coating of polymer mortar on the top surface to prevent the disintegration of concrete under various aggressive acids [10]. 
Under this test, RC dry weight is noted and is immersed with these two types of acids and observations are made on weekly basis for the colour changes.

The samples are washed in water after removing from acids and allowed to dry. It is then tested for compressive strength. Weight of the sample and its corresponding compressive strength were recorded. The results showed that no colour change found, no loss in weight, $7-7 \%$ reduction in strength at 28 days for nitric acid samples and slight colour change found at 28 days, 1 to $2 \%$ loss in weight, 5 to $10 \%$ reduction in strength at 28 days for sulphuric acid samples. There is no deterioration of concrete is found in both the acid samples.

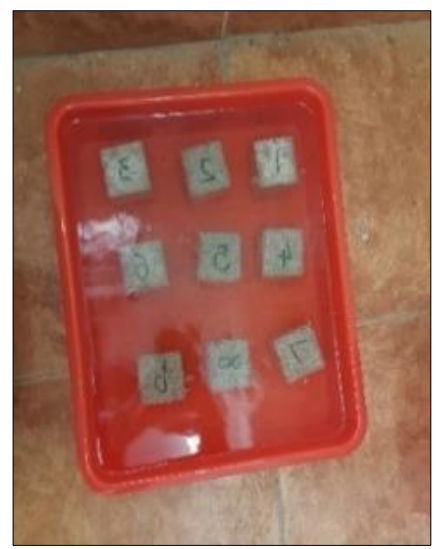

Figure 11. 40mm cubes immersed in $5 \%$ dil. Nitric acid

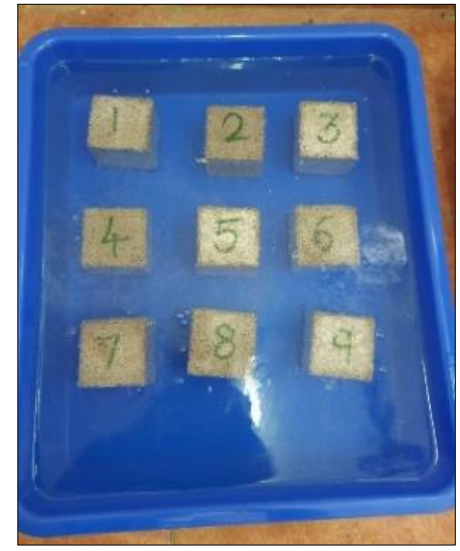

Figure 12. 40mm cubes immersed in $5 \%$ dil. Sulphuric acid

\subsection{Analytical investigation}

\subsubsection{Stress strain behaviour}

\subsubsection{Static Young's Modulus for RC}

The results showed that fiber reinforced fly ash based $O$ type resin exhibited improved mechanical properties than other shortlisted batches. Hence this finalized batch were taken for the study of typical stress strain behaviour, young's modulus, dynamic modulus, Poisson ratio, various correlations among their mechanical properties and durability properties. Stress strain behaviour for that batch and is shown in Figure 13.

Static young's modulus $\left(\mathrm{E}_{\mathrm{s}}\right)$ value from the stress strain curve is found to be $4.42 \mathrm{GPa}(641.07 \mathrm{ksi})$. Also the decrease in young's modulus shows the material is more elastic in nature and showed more strain value than the traditional concrete.

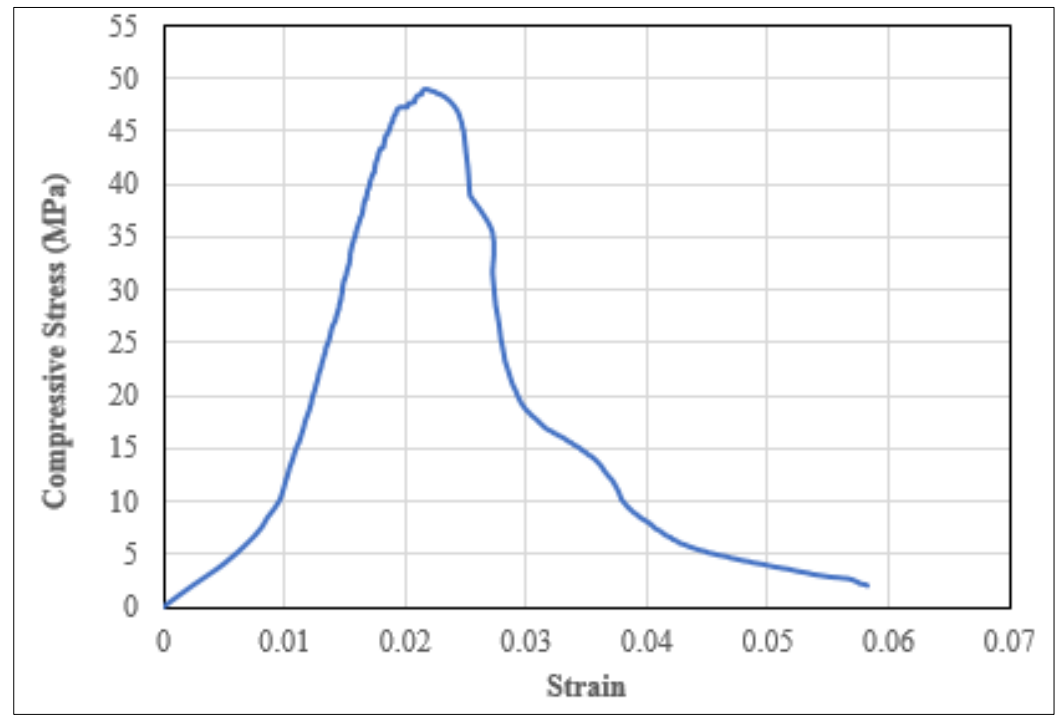

Figure 13. Typical stress strain behavior of O type fly ash based FRRC 


\subsubsection{Dynamic Young's Modulus for RC}

The dynamic young's modulus is calculated using the Ultrasonic Pulse Velocity test as per IS 11311(1): 1992 [11]. UPV test is carried out to determine the homogeneity, presence of cracks, voids, quality of concrete. The main principle of accessing the concrete using this method is, larger velocities are obtained if the material is having good quality, homogeneity and uniform concrete. If there is a presence of crack or any voids, these pulses travel through the path and make the path longer by getting lower velocity values. The dynamic Young's modulus of elasticity $\left(E_{d}\right)$ of the concrete may be determined from the pulse velocity (V) and the Poisson's ratio $\mu$, using the following relationship given in eq. (1)

$$
\mathrm{E}_{\mathrm{d}}=\frac{\rho(1+\mu)(1-2 \mu) V^{2}}{(1-\mu)}
$$

where:

$\mathrm{E}=$ dynamic young's modulus of elasticity in $\mathrm{MPa}$,

Density $(\rho)=2250$ in $\mathrm{Kg} / \mathrm{m}^{3}$,

$\mu=0.20$ obtained from stress strain curve,

$\mathrm{V}=$ Pulse velocity in $\mathrm{Km} / \mathrm{s}$.

All the UPV values obtained are well within the range of 4000 to $4200 \mathrm{~m} / \mathrm{s}$ and hence the concrete quality is good as per standards. Using the above equation the value of $\mathrm{E}_{\mathrm{d}}$ is calculated as $35.7 \mathrm{GPa}$ $(5177.85 \mathrm{ksi})$

\subsection{Correlative equations}

\subsubsection{Relationship between compressive strength and UPV}

The relationship is obtained for the optimized resin type $\mathrm{O}$ between their compressive strength $\left(\mathrm{f}_{\mathrm{ck}}\right)$ and ultra sonic pulse velocity, V (UPV) values. UPV test method is used to predict the strength of the concrete and the concrete quality. The test is carried out with the optimized developed mix and using their compressive strength values, analytical relationship between them is derived (Figure 14). The linear correlation coefficient $\left(\mathrm{R}^{2}\right)$ value is 0.948 , which is close to 1 . This indicates that the data is very close to the fitted regression line, and there is very little variability.

\subsubsection{Relationship between compressive strength and flexural strength}

Analytical equation of relationship between compressive and flexural strength is arrived for that finalised mix and the $\mathrm{R}^{2}$ value is 0.946 , which is almost forming a straight line and close to 1 showing less variability (Figure 15). Using these equations, the flexural strength of the samples can be calculated if the compressive strength is known. Theoretical relation and analytical relation between the flexural strength $\left(f_{r}\right)$ and compressive strength ( $f_{c}$ ) are given in equation (2) and equation (3) respectively.

Theoretical relation:

$$
\mathrm{f}_{\mathrm{r}}=1.72 \mathrm{f}_{\mathrm{c}}^{0.5} \mathrm{MPa}
$$

Analytical relation:

$$
\begin{gathered}
\mathrm{f}_{\mathrm{r}}=9.4156 \mathrm{f}_{\mathrm{c}}^{0.5}-69.847 \mathrm{MPa} \\
\mathrm{R}^{2}=0.946
\end{gathered}
$$




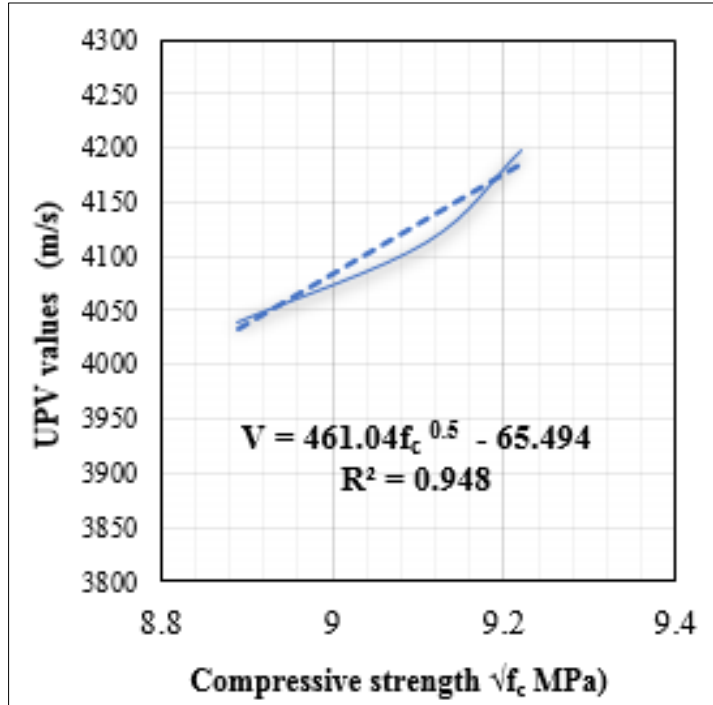

Figure 14. Correlation of compressive strength and UPV values

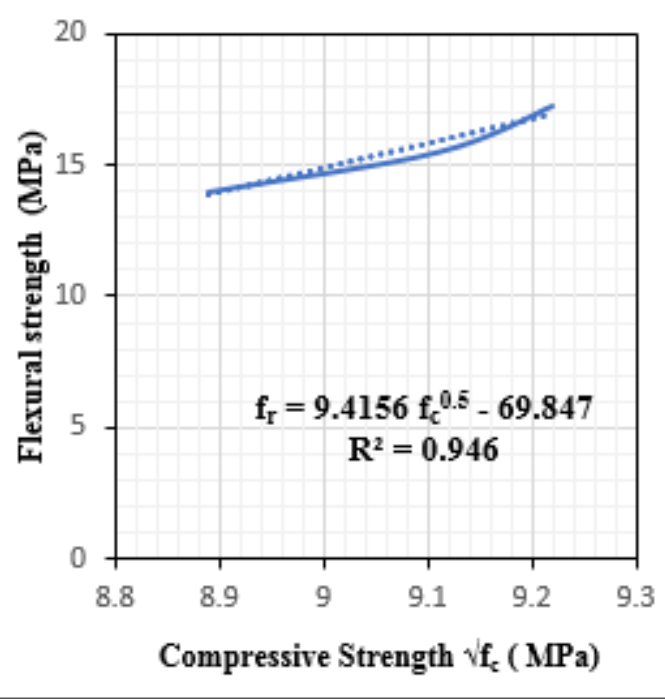

Figure 15. Correlation between compressive and flexural strength

\subsubsection{Relationship between compressive strength and split tensile strength}

Relationship between compressive strength and split tensile strength of the final optimised resin is derived by both means. Analytical equation is derived (Figure 16) from the graph values and mathematical expression for the same also been arrived. Using the below equations (4) and (5), value of tensile strength is known if the compressive strength is determined. Similar to other relationship equations, $R^{2}$ value is 0.9643 which is also equal to 1 .

Theoretical relation:

Analytical relation:

$$
\mathrm{f}_{\mathrm{t}}=1.46 \mathrm{f}_{\mathrm{c}}{ }^{0.5} \mathrm{MPa}
$$

$$
\mathrm{f}_{\mathrm{t}}=10.227 \mathrm{f}_{\mathrm{c}}^{0.5}-81.045 \mathrm{MPa}
$$

$$
\mathrm{R}^{2}=0.9643
$$

\subsubsection{Relationship between flexural strength and tensile strength}

Relationship between flexural strength and tensile strength of $O$ type FRRC is shown in Figure 17. Theoretical expression for the same also been arrived shown in equation (6) states that the tensile strength is approximately 1.3 times higher than corresponding tensile strength sample. Similar to other relationship equations, $\mathrm{R}^{2}$ value is 0.9292 which is also equal to 1 showing less variation.

Theoretical relation:

$$
\mathrm{f}_{\mathrm{r}}=1.28 \mathrm{f}_{\mathrm{t}} \mathrm{MPa}
$$

Analytical relation:

$$
\begin{gathered}
f_{r}=1.1311 f_{t}-6.0484 M P a \\
R^{2}=0.9292
\end{gathered}
$$




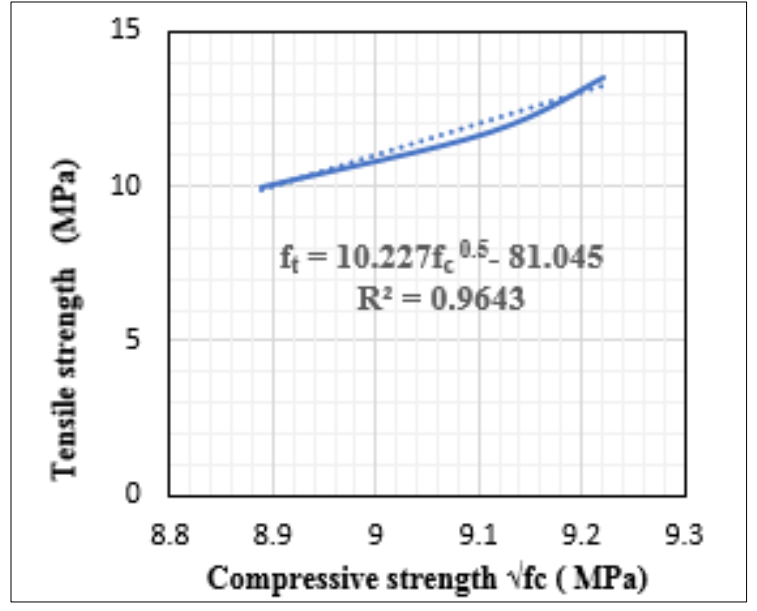

Figure 16. Correlation between split tensile and compressive strength

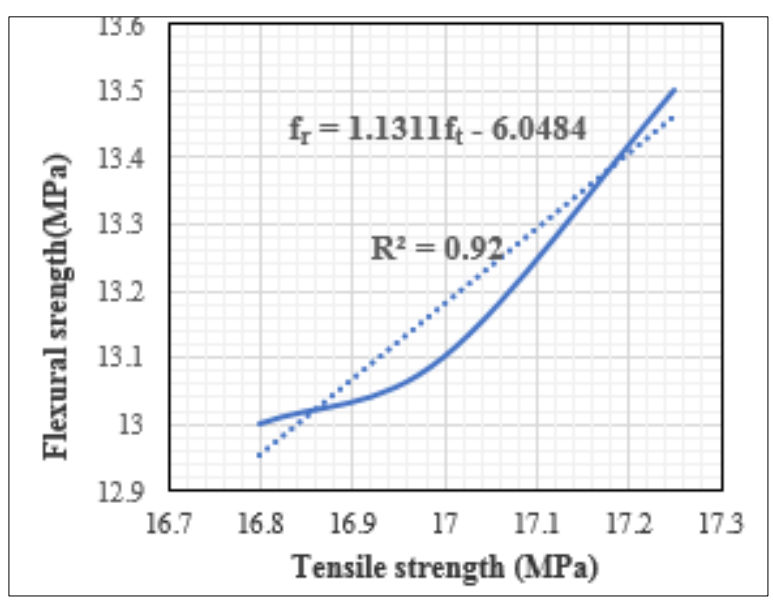

Figure 17. Correlation between split tensile and flexural strength

\section{Conclusions}

The study was conducted to investigate the various mechanical and durability properties of concrete under various environmental conditions and to derive the correlative equations to show the relationship between compressive strength and ultrasonic pulse velocity values, compressive strength and flexural strength, compressive strength and split tensile strength, flexural strength and split tensile strength. Based on the extensive study of Resin Concrete, the following conclusions can be underlined.

-Technology for fiber reinforced Resin concrete is developed with various properties like high strength $>80 \mathrm{MPa}(11.6 \mathrm{ksi})$ and high durability properties;

$-70 \mathrm{~mm}(2.76 \mathrm{inch}) \mathrm{VS} 40 \mathrm{~mm}(1.57 \mathrm{inch})$ cubes for the optimized mix and optimized materials showed slight increase in compressive strength of about 2 to $5 \%$ for $70 \mathrm{~mm}$ ( 2.76 inch) cubes compared to $40 \mathrm{~mm}$ ( $1.57 \mathrm{inch})$ cubes in both resin types due to better compaction of cubes. Hence $40 \mathrm{~mm}$ cubes are sufficient for study without fibers;

-Study of mechanical properties of optimised mix under different curing regime such as normal room temperature and samples cured at 80 degrees in oven for about $8 \mathrm{~h}$ shows increase in strength of about 4 to $7 \%$ of compressive strength for both types of resins;

-Albeit oven curing samples shows increase in strength, in order to cut down the cost of power supply which plays an additional cost during manufacturing process of various products using $\mathrm{RC}$, normal room temperature is preferred than oven curing;

-Relation between analytical and theoretical equation relation between the flexural strength, direct tensile strength, UPV values with compressive strength for the final optimized mix and material was achieved.

-Study of durability properties on RC shows there is no water absorption and acid tests shows the permissible reduction of strength in both acids however there is no reduction in mass and no deterioration of concrete was found in both the acid types;

-Developed fiber reinforced resin concrete mix possess various mechanical properties such as high compressive strength of $80 \mathrm{MPa}(11.6 \mathrm{ksi})$, flexural strength of $17.25 \mathrm{MPa}(2.5 \mathrm{ksi})$ and Tensile strength of about $13.5 \mathrm{MPa}(1.96 \mathrm{ksi})$ and high durability properties;

-This developed mix can be recommended for manufacturing various products in different industries such as FRP pipes in chemical \& petroleum plants, FRP covers, effluent storage tanks in Water treatment plants, power plant flooring tanks, swimming pools etc.

-Since the developed mix possess high mechanical properties and because of its nature of rapid curing of about within hours, this can be recommended for emergency mining jobs and repair works of bridges even without halting the traffic. 
Acknowledgments. The authors wish to express their gratitude and sincere appreciation to Department of Civil Engineering, SRM Easwari Engineering College for extending their support in Advanced Structural Engineering laboratory for developing this research work and testing using CTM which was provided by Government of India under the Scheme "Fund for Improvement of S\&T Infrastructure (FIST)" of the Department of Science \& Technology (DST) and also for the on-going research projects related to the development of various precast resin concrete products using this developed mix.

\section{References}

1.***ACI 548.1R-97, "Guide for the use of polymers in Concrete".

2.RAMAN BEDI, RAKESH CHANDRA, S. P. SINGH, (2013), Review of mechanical properties of polymer Concrete, Journal of Composites Volume 2013, Article ID 948745.

3.VICTOR Y. GARAS, C. VIPULANANDAN, Review of polyester polymer Concrete properties\|, Center for Innovative Grouting Materials and Technology (CIGMAT), Department of Civil and Environmental Engineering, University of Houston, Houston.

4.ANDRZEJ GARBACZ, JOANNA. J, SOKOLOWSKA, Concrete-like polymer composites with fly ashes- comparative study, Construction and building material Volume 38, January 2013, Pages 689-699 5.***Code book ASTM C618, "Standard Specification for Coal Fly Ash and Raw or Calcined Natural Pozzolan for Use in Concrete".

6.Y. OHAMA, "Mix proportions and properties of Polyester Resin Concretes", American Concrete Institute, pp. 283-294, 1973.

7.***Code book IS 516: 1959, "methods of tests for strength of concrete".

8.***Code book BS EN 12390-1:2012, "Testing hardened concrete Shape, dimensions and other requirements for specimens and moulds".

9.***Code book ASTM D570-98(2018), "Standard Test Method for Water Absorption of Plastics, ASTM International, West Conshohocken, PA, 2018".

10.***ACI 5152R-13, "Guide for the Protection of Concrete Against Chemical Attack by Means of Coatings and Other Corrosion-resistant Materials," ACI Journal, Proceedings V. 63, No. 12, December 1966, pages 13051392.

11.***Code book IS 13311(Part 1): 1992, "Non-Destructive Testing of Concrete - Methods of Test"

$\overline{\text { Manuscript received: } 16.07 .2021}$ 